\title{
Assessment of a railway concrete arch bridge by numerical modelling and measurements
}

\author{
G. He \& Z. Zou \\ Department of Civil, Environmental and Mining Engineering, Luleå University of Technology, Luleå, \\ Sweden \& Civil Engineering, Architecture College, Central South Forestry University, Changsha, \\ Hunan, P. R. China
}

O. Enochsson, A. Bennitz \& L. Elfgren

Department of Civil, Environmental and Mining Engineering, Luleå University of Technology, Luleå, Sweden

A. Kronborg, B. Töyrä \& B. Paulsson

Banverket, Borlänge \& Luleå, Sweden

ABSTRACT: Two main railway concrete arch bridges have been investigated in northern Sweden: the Vindel Bridge over the Vindel River with a span of $110 \mathrm{~m}$ and the Långforsen Bridge over the Kalix River with a span of $90 \mathrm{~m}$. The bridges were constructed in the 1950s with similar designs. In order to investigate the possibility to increase the axle load from $225 \mathrm{kN}$ to 250 kN, two 3-D Finite Element models with shell elements were developed and two field tests were carried out with passing trains and ambient vibrations. The measurement frequencies and mode shapes were studied with the stochastic subspace identification method in the time domain. Based on a comparison of the predictions of the FE analyses and the results of the field tests, the FE models were updated. It was found that it was possible to make good predictions of the actual dynamic response with reasonable assumptions of material properties and joint stiffness in the structure.

\section{INTRODUCTION}

Because of increases in axle loads and speeds, tougher environments and deteriorating materials, many existing bridges need to be assessed regarding their remaining service life. Consequently, many bridge engineers and researchers in the world are now faced with the challenge to develop innovative solutions to enhance the performance level or extend the service life of existing bridges.

In Sweden, the history of railroads started some 150 years ago. Many bridges have been in service more than 50 years, some even 100 years.

Two railway concrete arch bridges are discussed in this paper. The owner, Banverket, wanted to increase the maximum allowed axle load on them from $225 \mathrm{kN}$ to $250 \mathrm{kN}$. The Vindel Bridge crosses the Vindel River near Vindeln some $60 \mathrm{~km}$ NW of Umeå. It is a concrete arch bridge with a span of $110 \mathrm{~m}$ and a height of $22 \mathrm{~m}$, which was constructed in 1952, see Figure 1. The box rib arch carries a concrete deck with columns, see Figure 2. The section of the arch is a box with two cells. The width and height of the section varies with the distance from the abutment to middle span. Figure 3 shows a typical section of the box arch and the deck. The Långforsen Bridge, built in 1960, crosses the Kalix River at Långforsen. It is a similar concrete arch bridge as Vindel Bridge, with a span of $90 \mathrm{~m}$ and a height of $13.7 \mathrm{~m}$, see Figure 4 .

Large transversal movement was reported from visual site inspections on the Vindel Bridge. Arch bridges are complex structures whose structural form, which includes the shape and profile of the arch rib and sup-structures, results in significant three-dimensional structural responses. However, generally for assessment purposes conventional modelling methods use simplified two-dimensional beam element models. Here instead, mostly 3D shell elements will be used.

When a train passes over a bridge, dynamic effects will be induced in the bridge structure, especially for high speeds and heavy axle loads. Difficulties in the assessment of existing bridges arise from two primary reasons, the lack of knowledge about the conditions of the bridges, and the lack of accepted procedures for the analysis of existing bridges. 


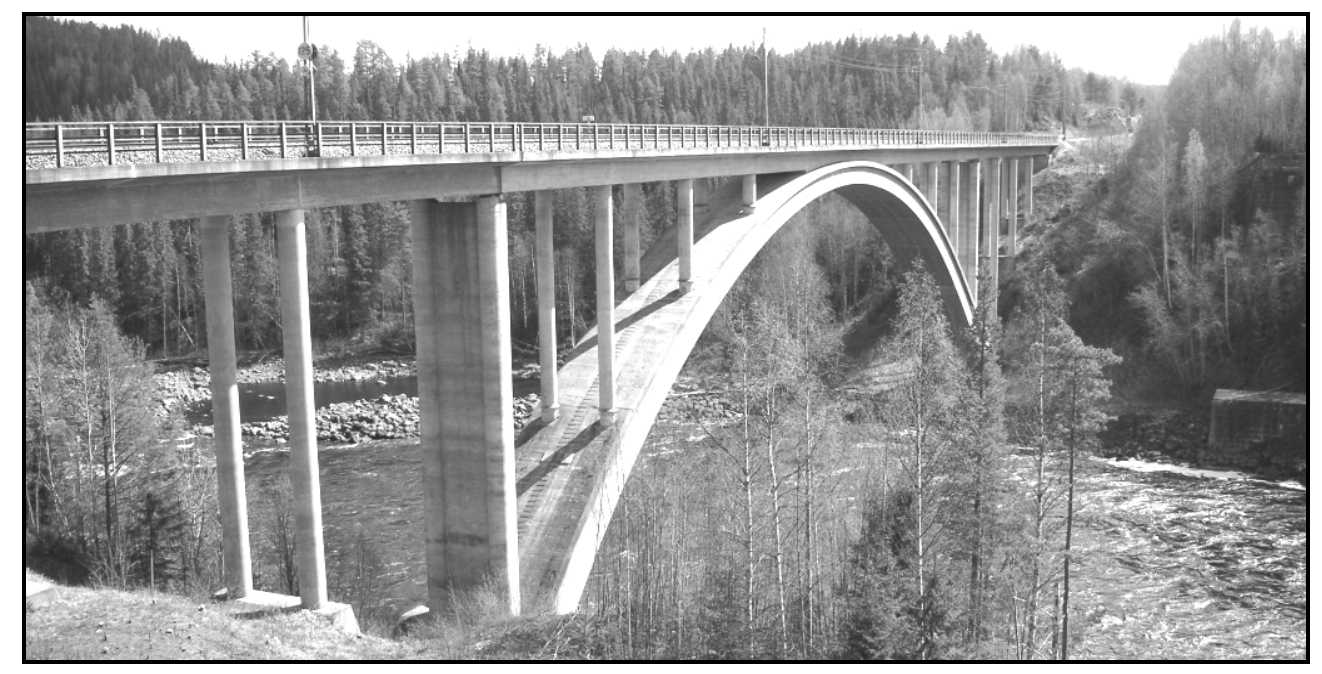

Figure 1. Bridge over the Vindel River in northern Sweden.

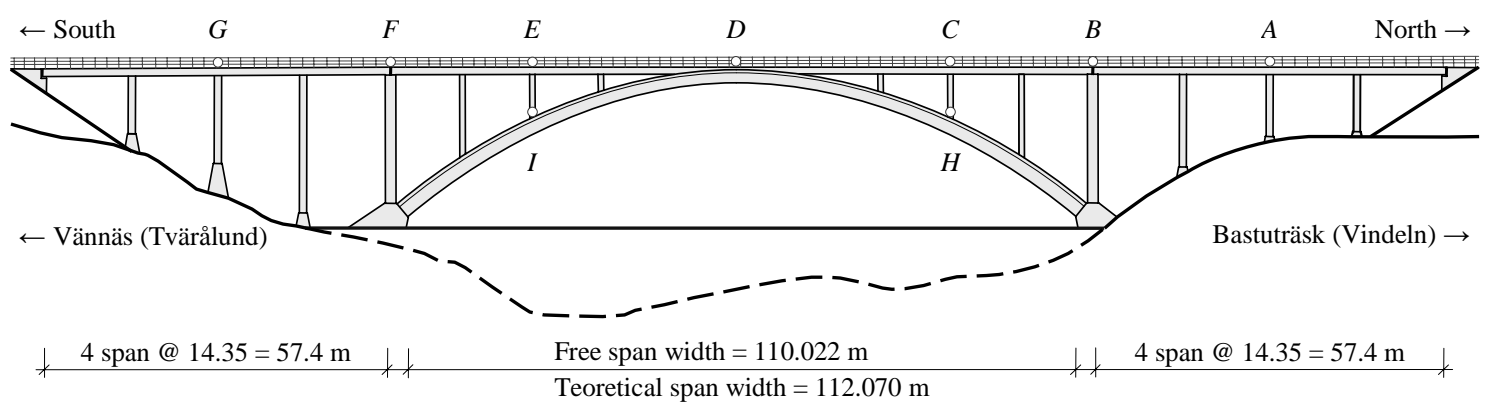

Figure 2. Elevation of the Vindel Bridge with location points of the sensors A-I.
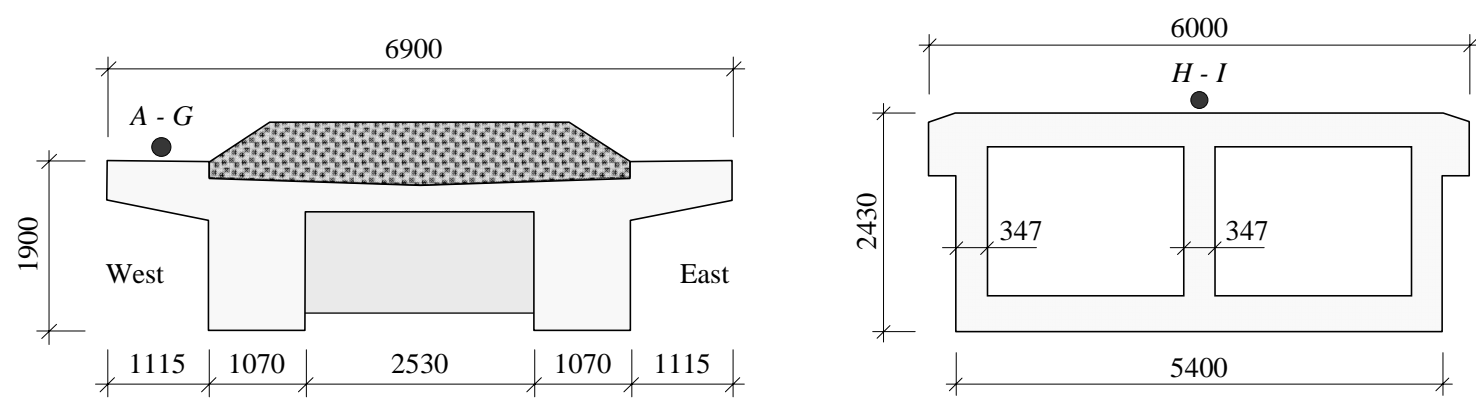

Figure 3. Vindel Bridge Cross Sections. Deck (left) and typical hollow box section of the arch (right), with location points for sensors A to I.

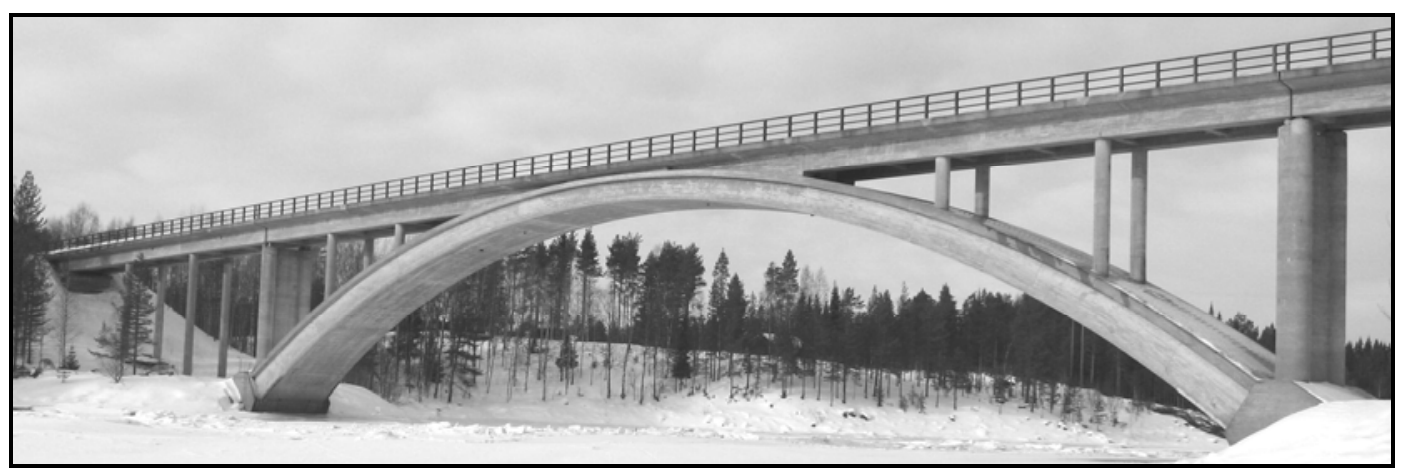

Figure 4. Bridge over the Kalix River at Långforsen in northern Sweden. 
A lot of research has been carried out on this subject, starting with works of Willis (1849) and Stokes (1849) in the middle of $19^{\text {th }}$ century; see e.g. Frýba (1996).

In this paper, two 3-Dimensional FE models with shell elements, different parameters of materials, connections of structures, and simulations of bearings, are used to obtain the computational dynamic behaviour (frequencies and mode shapes) and dynamic responses under moving trains. Most of the studies were done on the Vindel Bridge. Two field tests with service train loads and ambient vibrations in different natural conditions were carried out in September and December, 2005. The measurement frequencies and mode shapes were studied by the stochastic subspace identification method in the time domain. Based on a comparison between the results obtained by using the FE models and available field test results, the FE models were updated. At last, the causes of larger movement in the transverse direction were discussed and the possibility of increasing the axle load from $225 \mathrm{kN}$ to $250 \mathrm{kN}$ was checked.

\section{FIELD TESTS OF THE VINDEL BRIDGE}

Field tests were planned so that the bridge's dynamic behaviour, i.e., frequencies and mode shapes, could be investigated under ambient vibration and passing through train loading. Specific purposes were to investigate actual dynamic responses, i.e., displacement and acceleration under test train loading and different axle load distribution. Furthermore, the results of the field test were used to validate the finite element modelling.

\subsection{Instrumentation and test setup}

Two field tests were carried out in September and December, 2005, Bennitz (2006). In the first field test in September, two Linear Voltage Displacement Transducers (LVDT) were positioned in the longitudinal direction at the northern end point of the deck.

The other sensors, two horizontal sensors (Harbin 891 and 941B) and two vertical sensors (PCB piezotronics), were attached in pairs of one vertical and one horizontal to two steel tubes in each measurement position, see Figure 5. In the second field test in December, four vibration sensors (Harbin 891 and 941B), two LVDT's and two optical laser sensors (Noptel PSM200) were used to measure the response of the bridge. The Noptel PSM 200 receiver has a resolution of about $1 / 10 \mathrm{~mm}$ and records simultaneously horizontal and vertical movements of maximum $100 \mathrm{~mm}$.

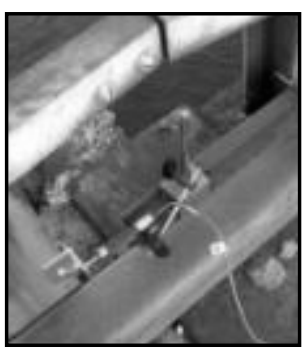

a) LVDT

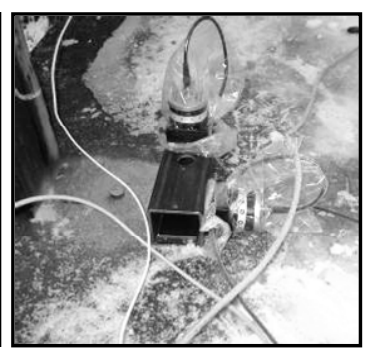

b) Vibration sensors

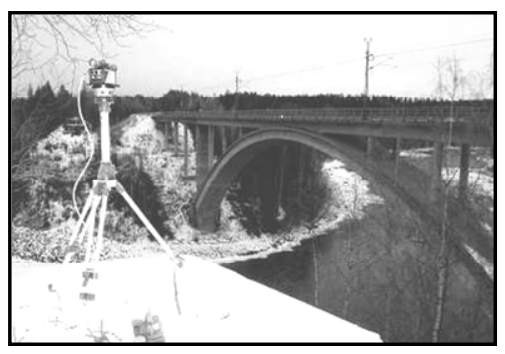

c) Laser displacement sensor, transmitter and receiver.

Figure 5 Instrumentation used in the two tests. Photo Anders Bennitz (2005).

\subsection{Frequencies and mode shapes}

To obtain the frequencies and corresponding mode shapes, the data of three sensors were used from the September test and four from the December tests. Because the input excitations are not measured, two complementary modal parameter identification techniques are used in this paper. One is the relatively new Stochastic Sub-space Identification (SSI) method in time domain, briefly introduced by Peeters and Roekeck (1999), and the other is the rather simple Peak Picking (PP) Technology in frequency domain.

The first 9 frequencies and corresponding mode shapes, which are the first 5 mode shapes in transverse and the first 4 mode shapes in vertical direction, have been obtain from the December 
data of. The first 7 frequencies and corresponding mode shapes, which are the first 5 mode shapes in transverse and the first 2 mode shapes in vertical, have been obtain from the September data.

\section{NUMERICAL MODELLING}

Railway arch bridges are complex structures involving interaction between the material, the superstructures, ballast, sleeper, rail, and railway equipment. Furthermore, the structural form of the bridge, which includes the rib, sup-structure and side spans, results in significant threedimensional structural responses. The contribution of these three-dimensional effects to the response of railway arch bridges has been noted, but is rarely discussed as important element of bridge assessment. Three-dimensional finite element models allow the analyst to account for the extent and geometry of each of these constituents in constructing a representative numerical model of arch bridge.

\subsection{Finite Element Models}

In this paper, the LUSAS (2005) finite element software was used to construct the models. A 3$\mathrm{D}$ beam model using beam elements were early developed to select the number of sensors and to decide the position of sensors for catching the dynamic behaviour. The beam model is calibrated with the 3-D shell model by using shell elements. For all of the FE models, the global coordinator system is set as the $\mathrm{x}$-axis in the longitudinal direction, the $\mathrm{y}$-axis in the vertical direction and the z-axis in the transverse direction; see Table 1 and Figure 5.

Table 1. Finite Element Models of the Bridge

\begin{tabular}{lllll}
\hline Model name & Deck & Arch & Column & Description \\
\hline Beam model & Beam element & Beam element & Beam element & Main and side span structure \\
Shell model & Shell element & Shell element & Beam element & Main and side span structure \\
\hline
\end{tabular}

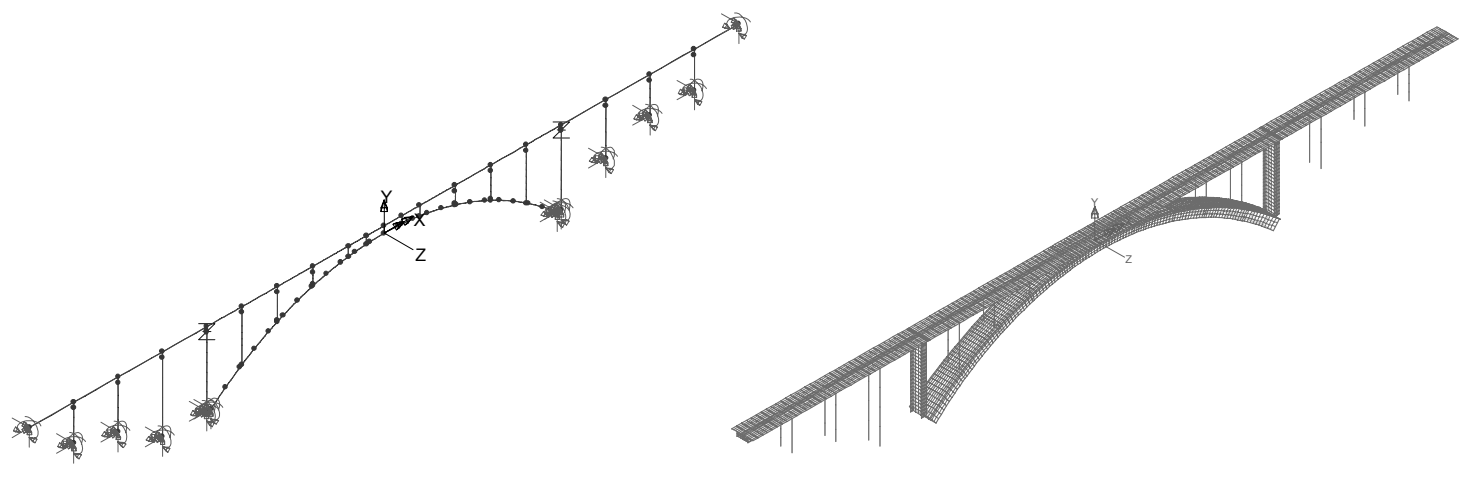

a) Beam model

b) Shell model

Figure 6. Three-dimensional Finite Element Models of the bridge.

In the beam models, arch ribs, columns and deck are modelled with 3-D beam elements. In the shell models, the arch rib, deck and end columns are modelled with 3-D shell elements. However, the other columns are still modelled with beam elements. All of the bearings are modelled by joint elements with different DOF (degree of freedom) and spring stiffness in both beam and shell models. The ballast and sleeper are modelled as masses without stiffness. The connection between the beams of the deck and the columns are modelled with 3-D beam elements with released end rotations. The ballast and sleeper are modelled as masses without stiffness. The concrete has a design compressive strength of $50 \mathrm{MPa}$ in the arch and the deck, and $40 \mathrm{MPa}$ in the columns. The modulus of elasticity has been assumed to have values of 35 and $33 \mathrm{GPa}$ respectively. Two additional FE models have been developed to study the effect of the super structure 
and the secondary dead load, such as ballast and railway equipment, on the dynamic behaviour, He et al (2006). In total, 1011 nodes and 509 elements are included in the beam model. In the shell model, 8624 nodes and 8514 elements are included.

\subsection{Dynamic response}

The calculated first 10 natural frequencies of vibration are listed in Table 2 and the first transverse and vertical mode shapes are illustrated in Figure 6. In general, the first 10 frequencies of the beam model are larger than for the shell model, and the order of modes after the $3^{\text {rd }}$ mode differ between the two models. The first vertical vibration mode in the shell model appears later than those in the beam model. The differences of the vertical frequencies are not as large as the differences of the transverse frequencies. The first two mode shapes of the two models are the same. The first frequency is $1.13 \mathrm{~Hz}$, corresponding to the first transverse mode shape. The frequency of the first mode shape in vertical is $2.46 \mathrm{~Hz}$.

Table 2. Ten first frequencies and mode shapes for beam and shell models

\begin{tabular}{lllll}
\hline No. & Shell model & & Beam model & \\
\cline { 2 - 5 } & Freq.[Hz] & Mode* $^{*}$ & Freq.[Hz] & Mode* $^{*}$ \\
\hline 1 & 1.13 & $\mathrm{~T}-1$ & 1.18 & $\mathrm{~T}-1$ \\
2 & 1.93 & $\mathrm{~T}-2$ & 2.47 & $\mathrm{~T}-2$ \\
3 & 2.23 & $\mathrm{~T}-3$ & 2.52 & $\mathrm{~V}-1$ \\
4 & 2.46 & $\mathrm{~V}-1$ & 3.23 & $\mathrm{~T}-3$ \\
5 & 3.25 & $\mathrm{~T}-4$ & 3.59 & $\mathrm{~V}-2$ \\
6 & 3.46 & $\mathrm{~V}-2$ & 4.38 & $\mathrm{~T}-4$ \\
7 & 4.19 & $\mathrm{~T}-5$ & 4.72 & $\mathrm{~V}-3$ \\
8 & 4.71 & $\mathrm{~V}-3$ & 5.91 & $\mathrm{~V}-4$ \\
9 & 5.26 & $\mathrm{~T}-6$ & 6.39 & $\mathrm{~T}-5$ \\
10 & 5.64 & $\mathrm{~V}-4$ & 6.49 & $\mathrm{~T}-6$ \\
\hline
\end{tabular}

* T: transverse global vibration.

$\mathrm{V}$ : vertical global vibration

From Table 2, it can be seen that the beam model is stiffer than the shell model. The reason may be that the columns, the deck and beam are modelled in a different way in the beam model and the shell model. The shell model is used to study the dynamic behaviour and to simulate the dynamic response of the bridge when a freight carriage passes through. The modelling of connections of components, especially the bearings, is important for the numerical model of a bridge structure. Based on the above beam and shell models, the effects of different type of bearings and the connection between the deck beam and the column on the dynamic behaviour have been investigated, for more details see He et al (2006). The connection between the deck beam and the shorter columns are modelled with a joint for which the rotation degree about the z-axis has been released.

In order to calibrate the calculated results with measurement in September and December, the joint element is used to simulate the bearings with movable and fixed joint at the two ends of the deck beam in the FE models. The movable joint bearings are used in the shell model corresponding to field test in September as S-Sep, whereas, the fixed joint bearings are used in the shell model corresponding to field test in December as S-Dec. The calculated first 10 natural frequencies of vibration mode with S-Sep and S-Dec are list in Table 3.

The frequency and the order of the mode shape are very different for S-Sep and S-Dec. The movable joint bearing results in a reduction of frequencies of each vibration mode and a change of order of the mode shapes. The effect of the bearing on the mode shapes and frequencies is significant. However, the effect of the released rotation degree about the z-axis is just to bring the local mode shapes related to the columns. It is noteworthy that the bridge has the lowest frequency in relation to transverse bending, meaning that the bridge is affected more easily by lateral loading than by vertical loading. 
Table 3. Ten first frequencies and mode shapes estimated from the two tests.

\begin{tabular}{lllll}
\hline No. & \multicolumn{2}{l}{ S-Dec (fixed joints) } & \multicolumn{2}{l}{ S-Sep (movable joints) } \\
\cline { 2 - 5 } & Freq.[Hz] & Mode & Freq.[Hz] & Mode \\
\hline 1 & 1.13 & T-1 & 1.11 & T-1 \\
2 & 1.93 & T-2 & 1.62 & V-1 \\
3 & 2.23 & T-3 & 1.78 & T-2 \\
4 & 2.46 & V-1 & 2.00 & T-3 \\
5 & 3.25 & T-4 & 3.08 & T-4 \\
6 & 3.46 & V-2 & 3.43 & V-2 \\
7 & 4.19 & T-5 & 3.82 & T-5 \\
8 & 4.71 & V-3 & 4.69 & T-6 \\
9 & 5.26 & T-6 & 4.70 & V-3 \\
10 & 5.64 & V-4 & 4.93 & V-4 \\
\hline
\end{tabular}

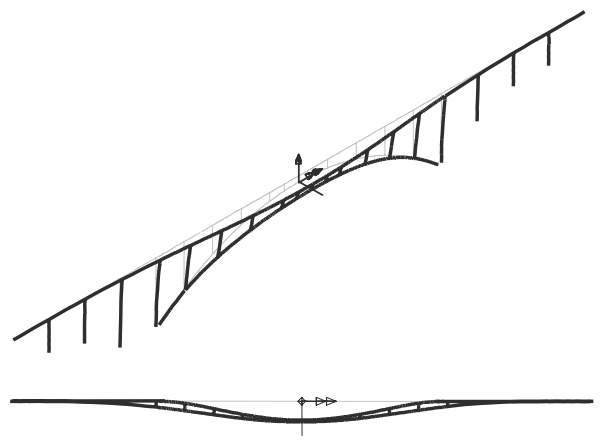

a) First transversal bending mode, T-1

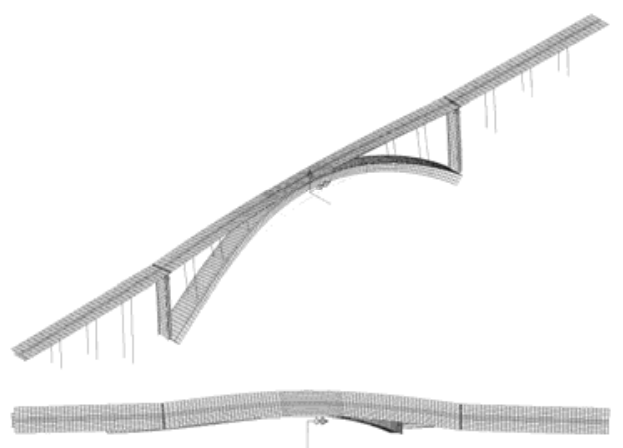

c) First transversal bending mode, T-1

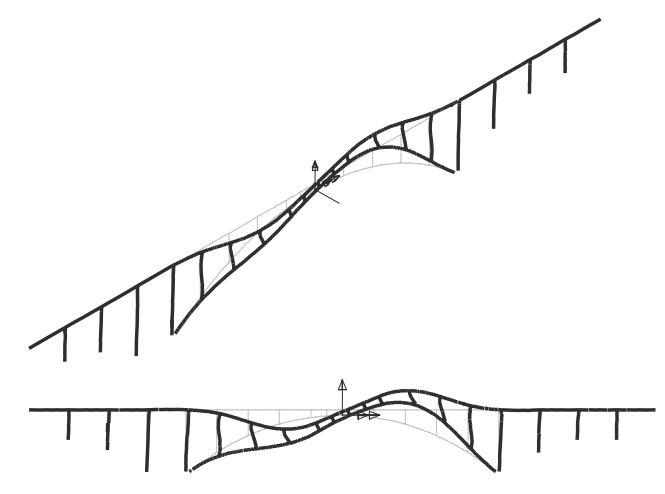

b) First vertical bending mode, V-1

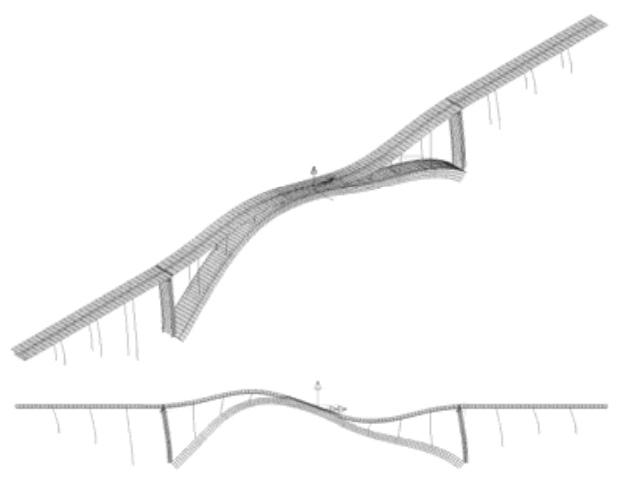

d) First vertical bending mode, V-1

Figure 7. First mode shapes estimated with a-b) the beam model, and c-d) the shell model.

\section{COMPARISON AND DISCUSSION}

\subsection{Validation of the finite element models}

To validate the FE models, the calculated dynamic behaviour from different FE models are compared to the test results from September and December 2005. For the purpose of comparison, the frequencies of test and calculated results are given in Table 4 and Figure 9 . The results of S-Dec and S-Sep agree well with the results of measurements in December and September respectively, especially for the frequencies of transverse vibration modes. It shows that the existing railway arch bridge can be modelled reasonably well by shell models with different modelling for the bearings and connections. 
Table 4. The first 10 frequencies and mode shapes estimated from FE models (S-Sep and S-Dec) and field test (M-Sep and M-Dec) in September and December 2005, respectively.

\begin{tabular}{|c|c|c|c|c|c|c|c|c|}
\hline \multirow[t]{2}{*}{ No. } & \multicolumn{2}{|c|}{ S-Dec } & \multicolumn{2}{|c|}{ S-Sep } & \multicolumn{2}{|c|}{ M-Dec } & \multicolumn{2}{|c|}{ M-Sep } \\
\hline & $\begin{array}{l}\text { Freq } \\
{[\mathrm{Hz}]}\end{array}$ & Mode & $\begin{array}{l}\text { Freq } \\
{[\mathrm{Hz}]}\end{array}$ & Mode & $\begin{array}{l}\text { Freq } \\
{[\mathrm{Hz}]}\end{array}$ & Mode & $\begin{array}{l}\text { Freq } \\
{[\mathrm{Hz}]}\end{array}$ & Mode \\
\hline 1 & 1.13 & $\mathrm{~T}-1$ & 1.11 & $\mathrm{~T}-1$ & 1.15 & $\mathrm{~T}-1$ & 1.11 & $\mathrm{~T}-1$ \\
\hline 2 & 1.93 & $\mathrm{~T}-2$ & 1.62 & $\mathrm{~V}-1$ & 1.90 & $\mathrm{~T}-2$ & 1.77 & $\mathrm{~T}-2$ \\
\hline 3 & 2.23 & $\mathrm{~T}-3$ & 1.78 & $\mathrm{~T}-2$ & 2.25 & $\mathrm{~T}-3$ & 2.05 & $\mathrm{~T}-3$ \\
\hline 4 & 2.46 & V-1 & 2.00 & $\mathrm{~T}-3$ & 2.57 & V-1 & 2.21 & $\mathrm{~V}-1$ \\
\hline 5 & 3.25 & $\mathrm{~T}-4$ & 3.08 & $\mathrm{~T}-4$ & 3.44 & $\mathrm{~T}-4$ & 3.19 & $\mathrm{~T}-4$ \\
\hline 6 & 3.46 & $\mathrm{~V}-2$ & 3.43 & $\mathrm{~V}-2$ & 3.80 & $\mathrm{~V}-2$ & 3.72 & $\mathrm{~V}-2$ \\
\hline 7 & 4.19 & $\mathrm{~T}-5$ & 3.82 & $\mathrm{~T}-5$ & 4.60 & $\mathrm{~T}-5$ & 3.99 & $\mathrm{~T}-5$ \\
\hline 8 & 4.71 & V-3 & 4.69 & T-6 & 5.40 & V-3 & & \\
\hline 9 & 5.26 & $\mathrm{~T}-6$ & 4.70 & V-3 & 6.50 & $V-4$ & & \\
\hline 10 & 5.64 & $V-4$ & 4.93 & $V-4$ & & & & \\
\hline
\end{tabular}

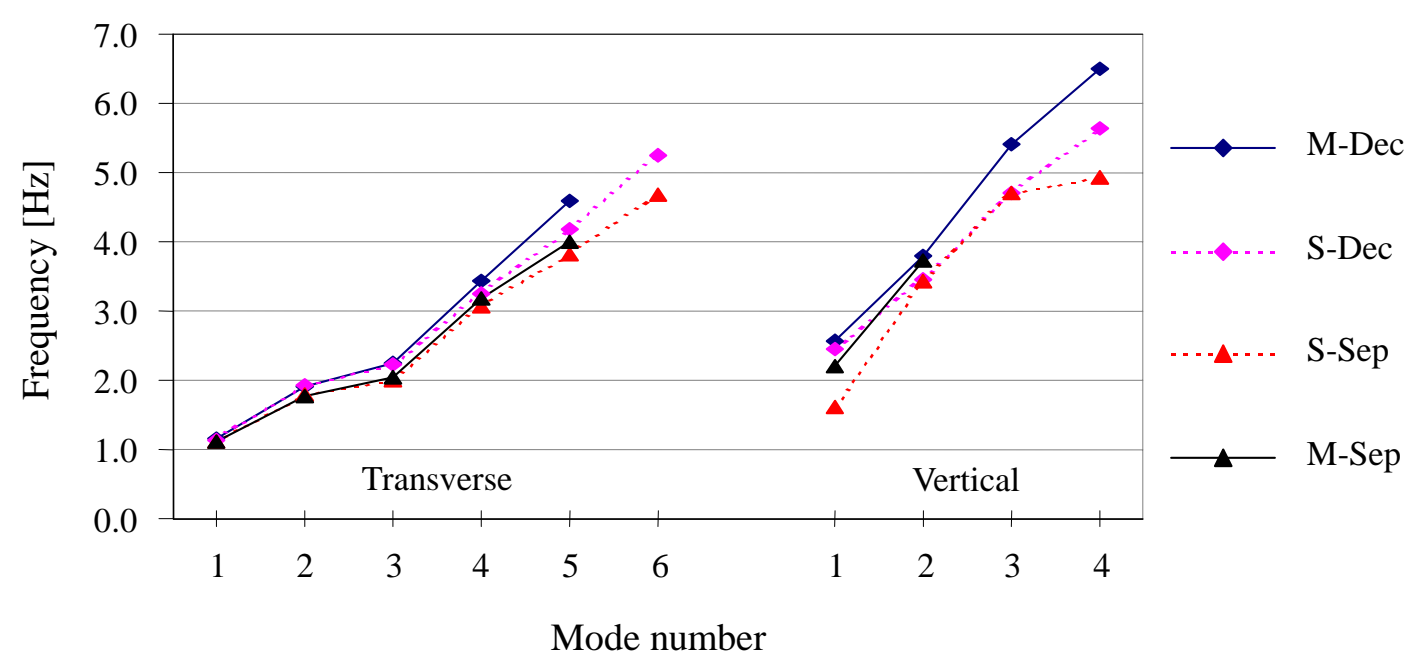

Figure 9 Comparison of frequencies calculated with FE models and measured in field tests.

The shapes of the modes calculated with model S-Dec and model S-Sep are the same as the measured ones. The percentage errors of frequencies between the two calculated models and measured results are about $10 \%$, except for the first frequency of vertical mode in model S-IVSep. The first frequency of vibration is $1.11 \mathrm{~Hz}$ and $1.13 \mathrm{~Hz}$ in September and December, respectively. The situation of the bridge is changed with the working state of bearings in different seasons. So, the models of S-Dec and S-Sep will be used to calculate the dynamic response of the Vindel River Bridge under different load cases.

\subsection{Dynamic response of the bridge}

Based on the measurements in September and December, the FE models were updated, He et al (2006a-b), and used to investigate the influence of an increased train load from 225 to $250 \mathrm{kN}$, i.e. the standard type D2 to BV-3 according to the code (BV Bro 2004 \& BV Bärighet 2005). Furthermore, the dynamic responses of the bridge with the shell models (S-Dec and S-Sep) are calculated with four load cases see Table 5, which were simulated with the IMD-Plus modular by a sequential series of load steps. Different velocities were studied from $10 \mathrm{~m} / \mathrm{s}$ to $35 \mathrm{~m} / \mathrm{s}$, i.e., $36 \mathrm{~km} / \mathrm{h}$ to $126 \mathrm{~km} / \mathrm{h}$, which are close to the speed limit of $120 \mathrm{~km} / \mathrm{h}$. The maximum axle load of $250 \mathrm{kN}$ corresponds to the maximum allowed load capacity according to Banverket (the Swedish Railway Administration), and the transverse load is $8 \%$ of this axle load. 90 free vibration modes up to $25 \mathrm{~Hz}$ and 2400-12000 time steps with a time interval of 0.0025 seconds are 
included in this simulation. The typical responses of time-history for displacement and acceleration calculated with FE models are shown in Figure 10.

Table 5. Load cases.

\begin{tabular}{llcc}
\hline No. & Load cases & No of locomotives & Axle load [kN] \\
\cline { 2 - 4 } 1 & D-2 & 3 & 225 \\
2 & BV-3 & 3 & 250 \\
3 & Steel train & 3 & 250 \\
4 & Test steel train & 2 & 225 \\
\hline
\end{tabular}

In the field test, the bridge dynamic response under three types of passing trains has been measured: locomotives with 90 tons, steel freight train and timber freight train. Figure 11 shows the typical responses of time-history for displacements.

The maximum measured and calculated displacements are summarized in Table 6 to 8 .

Table 6. Summary of measured maximum displacement [mm]

\begin{tabular}{lllllll}
\hline \multirow{2}{*}{$\begin{array}{l}\text { Location in } \\
\text { arch span }\end{array}$} & \multicolumn{2}{l}{ Locomotive } & \multicolumn{2}{l}{ Test train (steel) } & \multicolumn{2}{l}{ Test train (Freight) } \\
\cline { 2 - 7 } & Vertical & Transverse & Vertical & Transverse & Vertical & Transverse \\
\hline Middle & 1.3 & 0.5 & 2.8 & 0.7 & 2.6 & 1.3 \\
Quarter & 1.8 & 0.5 & 3.6 & 0.5 & 3.2 & 0.7 \\
\hline
\end{tabular}

Table 7. Summary of calculated maximum transverse displacement [mm]

\begin{tabular}{lllll}
\hline Location in arch span & BV-3 & D2 & Steel train & Test train \\
\hline Middle (1/2) & 5.14 & 4.13 & 4.01 & 3.82 \\
Quarter (1/4) & 4.51 & 3.62 & 3.52 & 3.35 \\
Quarter (3/4) & 4.47 & 3.32 & 3.49 & 3.32 \\
End & 2.86 & 2.14 & 2.23 & 2.14 \\
\hline
\end{tabular}

Table 8. Summary of calculated maximum vertical displacement [mm]

\begin{tabular}{lllllllll}
\hline \multirow{2}{*}{$\begin{array}{l}\text { ocation in } \\
\text { arch span }\end{array}$} & \multicolumn{2}{c}{ BV-3 } & \multicolumn{2}{c}{ D2 } & \multicolumn{2}{c}{ Steel train } & \multicolumn{2}{c}{ Test train } \\
\cline { 2 - 9 } & S-Dec & S-Sep & S-Dec & S-Sep & S-Dec & S-Sep & S-Dec & S-Sep \\
\hline Middle (1/2) & 4.02 & 4.02 & 3.24 & 3.27 & 3.11 & 3.14 & 3.11 & 2.98 \\
Quarter (1/4) & 4.03 & 6.23 & 4.07 & 6.21 & 4.02 & 6.23 & 4.01 & 5.70 \\
Quarter (3/4) & 5.39 & 8.36 & 4.41 & 6.65 & 4.25 & 6.49 & 4.19 & 6.22 \\
\hline
\end{tabular}
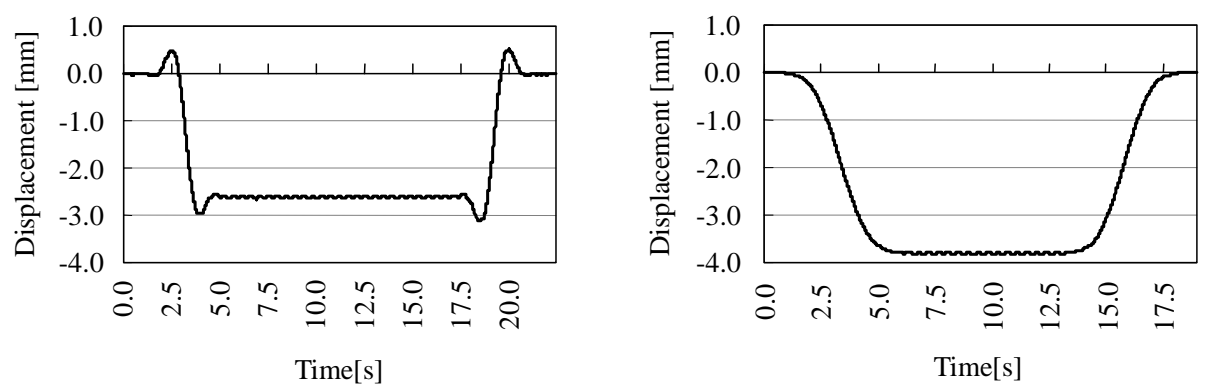

Figure 10. Vertical and transversal displacements in the centre of the deck in main span (point D) when two test steel train (axle load $=225 \mathrm{kN}$ ) are passing the bridge with about $126 \mathrm{~km} / \mathrm{h}$. 

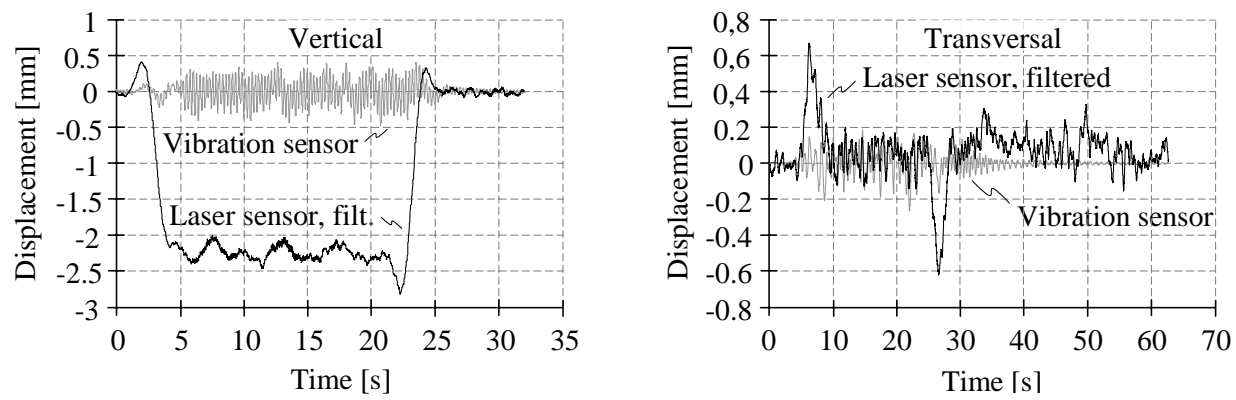

Figure 11 Vertical and transversal displacements in the center of the deck in main span (point D) when two individual steel freight train (axle load $=225 \mathrm{kN}$ ) are passing the bridge with about $100 \mathrm{~km} / \mathrm{h}$. The laser sensors measure both the static and dynamic part of the displacement while the vibration sensors only measure the dynamic part, Bennitz (2006).

\subsection{Discussion of results}

The updated numerical FE models, shell models of S-Dec and S-Sep, developed in this paper are clearly capable of predicting the existing railway concrete arch bridge dynamic behaviour and response for passing trains. The calculated frequencies of free vibration in transverse and vertical direction compare very favourably with measured frequencies. The dynamic response was also found to be linear elastic within the service axle load $225 \mathrm{KN}$ and increased axle load 250KN.

The first frequencies of free vibration mode are 1.11 and $1.15 \mathrm{~Hz}$ in the transverse direction in September and December, respectively, whereas the calculated frequencies are 1.11 and 1.13 $\mathrm{Hz}$ with the same vibration mode. The first frequency of free vibration in the vertical direction are 2.21 and $2.57 \mathrm{~Hz}$ in September and December, respectively, and is $4^{\text {th }}$ vibration mode in total vibration modes. The modelling of bearing and connections has a significant effect on predicting the bridge dynamic behaviour with different season, especially for the northern regions in Sweden. It is also noteworthy that the bridge has the lowest frequency in relation to transverse bending, meaning that the bridge is affected more easily by lateral loading than vertical loading. Furthermore, during inspections, dynamic vibrations were observed in the transverse direction from passing trains. In the swedish design code, the transverse load is taken as a concentrated load of $80 \mathrm{kN}$. In fact, the lateral dynamic load, which should be dealt with as a random load, is different from the vertical load which can be taken as definite load. So, at first, the calculated result can be used as a guidance for measurements in, and then, for calibrations.

The measured maximum displacement in the vertical direction was $3.6 \mathrm{~mm}$ at the quarter span of the arch for a passing steel train. The maximum displacement in the transverse direction was $1.3 \mathrm{~mm}$ at the middle span of the arch under a passing freight train, which was a light than steel train.

In December, the calculated maximum vertical displacement for a test train was $4.19 \mathrm{~mm}$ at the quarter span of the arch with model S-Dec. The maximum displacement in the vertical direction under the BV-3 (axle load of $250 \mathrm{kN}$ ) was $5.39 \mathrm{~mm}$ at the same position as the passing steel train.

The increase of the displacement in the vertical direction from test train to BV-3 was 28.6. The ratio of vertical displacement to span is very small. The vertical stiffness should be enough to allow an increase of the axle load from $225 \mathrm{KN}$ to $250 \mathrm{kN}$. However, the calculated maximum displacements in the transverse direction were $3.82 \mathrm{~mm}$ and $5.14 \mathrm{~mm}$ at the middle span of the arch under the test train and BV-3, respectively. The increase of the displacement in the transverse direction was 35.2.

\section{CONCLUSIONS}

Measurements carried out in September and December 2005 gave the lowest frequency to 1.11 and $1.15 \mathrm{~Hz}$ respectively for the transverse global vibration, the higher frequency in December probably due to increased stiffness caused by frozen ballast and concrete. The largest vertical 
displacement was caused by a steel freight train and the largest transversal displacement was caused by a timber freight train. The transverse, as well as the vertical dynamic vibration is highly dependent on the composition of the carriers. A light, but bad composed train, can cause larger transverse motion than a heavy steel train.

Railway arch bridge under passing trains and ambient vibrations exhibit a complex threedimensional response. Commercially available three-dimensional finite element software can be implemented to predict the effect of bearings, connection of structures and load distribution on the dynamic behaviour and response. However, the FE model should be updated with field test results to decrease the modelling error. The FE shell models of S-Sep and S-Dec in this paper are updated with the field test in September and December, 2005. The calculated frequencies and dynamic responses agree well with the measured results. It shows also that the bridge was affected more easily by a lateral loading than by a vertical loading, especially under dynamic load cases.

The displacements in vertical and transverse directions are acceptable under the test train and BV-3 train with axle load of $250 \mathrm{kN}$, at least, in the limit of the applied code. The dynamic responses show that the vertical stiffness is enough to allow an increase of the axle load from 225 $\mathrm{kN}$ to $250 \mathrm{kN}$.

The transverse stiffness of the bridge can be improved distinctly by an increase of the stiffness of the end columns. Based on the calculated and measured results, the transverse stiffness should also allow an increase of the axle load from $225 \mathrm{kN}$ to $250 \mathrm{kN}$.

Because of the stochastic character in magnitude and direction of the transverse axle load applied to the rail, further investigations are suggested with field tests for the bridges. Based on the probabilistic method, the stochastic properties of a structure, such as geometric dimensions, material strength, cracks distribution, mass density, bearing conditions, connection components, and Young's modulus can be considered in assessment of the bridges.

\section{REFERENCES}

BBK 04 (2004): Boverkets handbok om betongkonstruktioner (2004). (The Swedish Building Administration's Handbook on Concrete Structures). Stockholm, Sweden: The Swedish Building Administration, Division of Buildings, August 2004 (In Swedish).

Bennitz, Anders (2006): Dynamic Behaviour of the Vindel River Railway Bridge - Measurements and Evaluation for Displacements and Eigenfrequencies. Div. of Structural Engineering, Luleå University of Technology. Master of Science Thesis 2006:154 CIV. ISSN: 1402-1617.

BV Bärighet (2005): Bärighetsberäkning av järnvägsbroar (Assessment of Railway Bridges. In Swedish). Handbok BVS 583.11. Banverket, CB, Borlänge 2005-06-01, 108 pp + 9 app.

Frýba, L. (1996): Dynamics of Railway Bridges. London: Thomas Telford

He, G.J., Bennitz, A., Enochsson, O. \& Elfgren, L. (2006a). The Vindel Railway Bridge. Analysis and Measurements. Tech. Report. Div. of Struct. Eng, Luleå University of Technology (to be published).

He, G. J.; Bennitz, A.; Enochsson, O.; Elfgren, L.; Paulsson, B.; Töyrä, B.; Olofsson, P. and Kronborg, A. (2006b): Numerical modeling and dynamic behavior of a railway concrete bridge over the Vindel River in Sweden. Proc 3rd Int Conf on Bridge Maintenance, Safety and Management (IABMAS’06), Porto, Portugal, 16-19 July 2006. Taylor \& Francis Group, London, Abstract pp 327-328. (Full paper P-104, 8 p, on attached CD). ISBN 0415403154.

LUSAS (2005): Powerful FE technology for specialist application, Modeller User Manual, United Kingdom

Peeters, B. and De Roeck, G. (2001): Stochastic system identification for operational modal analysis: a review, Journal of Dynamic Systems, Measurement, and Control, 123, 659-667.

Stokes, G.G. (1849): Discussion of a differential equation relating to the braking of railway bridges, Transactions of the Cambridge Philosophical Society, 8(5): 707-735.

Willis, R. (1849): Appendix to the report of the Commissioners Appointed to Inquire into the Application of Iron to Railway, H. M. Stationary Office, London, United Kingdom. 